\title{
The paradox of Metridia spp. egg production rates: a new technique and measurements from the coastal Gulf of Alaska
}

\author{
R. R. Hopcroft", C. Clarke, A. G. Byrd, A. I. Pinchuk \\ Institute of Marine Science, University of Alaska, Fairbanks, Alaska 99775, USA
}

\begin{abstract}
Egg production rates of the copepods Metridia pacifica and M. okhotensis were examined in the Gulf of Alaska over an annual cycle using a new incubation system that separates females from their eggs and keeps the eggs undisturbed prior to observation. Metridia spp. eggs frequently break-down during incubation, leading to severe underestimates of egg production by traditional methods. Egg production by M. pacifica continued throughout most of the year, while that of M. okhotensis was confined to the spring. Egg production rates of $M$. pacifica peaked in May at 30 eggs female ${ }^{-1} \mathrm{~d}^{-1}$ and averaged 16 eggs female $\mathrm{e}^{-1} \mathrm{~d}^{-1}$ from March through October. Egg production of M. okhotensis was limited to spring and averaged 28 eggs female $\mathrm{e}^{-1} \mathrm{~d}^{-1}$ during April and May. Equivalent specific egg production rates for the 2 species over these periods averaged 10 and $11 \%$, respectively, comparable to other calanoid species from this region. For M. pacifica, most of the variability in egg production rates could be attributed to ambient chlorophyll concentrations, after adjusting for the influence of temperature, with food-saturated specific egg production at $5{ }^{\circ} \mathrm{C}$ equivalent to 17 to $18 \%$ of their body weight $\mathrm{d}^{-1}$, and half saturation occurring at 1 to $1.5 \mathrm{mg}$ chlorophyll $\mathrm{a} \mathrm{m}^{-3}$.
\end{abstract}

KEY WORDS: Egg production $\cdot$ Metridia pacifica $\cdot$ Metridia okhotensis $\cdot$ Alaska $\cdot$ Techniques

\section{INTRODUCTION}

Although plankton ecologists have been preoccupied with the biology of copepods for nearly a century, this effort has concentrated on only a handful of species that are either primarily coastal, or members of the family Calanidae (see Mauchline 1998). Metridia is among these neglected calanoid genera, and is often poorly represented in collections because it undergoes a strong diel migration (e.g. Batchelder 1985, Hirakawa \& Imamura 1993). Metridia species occur throughout the world's oceans in temperate through sub-polar waters (Brodsky 1967), being among the more common medium- to large-bodied copepods in many regions (e.g. Smith \& Vidal 1986, McLaren et al. 1989, Huntley \& Escritor 1992, Incze et al. 1997, Sherman et al. 1998, Rebstock 2001, Hopcroft et al. 2002).

Throughout the North Pacific, Metridia pacifica is the most common species within the genus (Brodsky
1967), but the larger M. okhotensis is also relatively common, especially in deep, semi-enclosed systems such as the Okhotsk Sea (Brodsky 1967, 1977, Shebanova 1997), the deep Bering Sea (Ozaki et al. 2001), and fjords in the north-eastern Pacific (Gardner \& Szabo 1982), including Alaskan coastal embayments (Coyle et al. 1990, Cooney et al. 2001). In the Gulf of Alaska, where sampling has been conducted consistently during night-time, Metridia species rank second in larger-bodied copepod abundance after Neocalanus species during spring and early summer, but typically rank first for the remainder of the year (Coyle \& Pinchuk 2003).

To be such a prominent species, one would expect Metridia to have egg production rates comparable to other dominant broadcast spawning species. Paradoxically, the measured rates of egg production for $M$. pacifica have been consistently low (e.g. Batchelder \& Miller 1989, Hirakawa \& Imamura 1993). Preliminary 
incubations of Metridia species in the Gulf of Alaska suggested similarly low egg production; yet it was also observed that eggs laid in multi-well plates had usually disappeared by subsequent inspections. Egg cannibalism was implicated, so egg production 'towers' were designed that employed Nitex screens to separate the females from any eggs that they laid. Unlike most anti-cannibalism systems, these towers could be dismantled allowing observation of the eggs without disturbance. Here we report the rates and seasonal cycles of egg production for both $M$. pacifica and M. okhotensis species using these techniques.

\section{MATERIALS AND METHODS}

The study area in the northern Gulf of Alaska is part of the US Northeast Pacific GLOBEC program (see Weingartner et al. 2002). The region is characterized by a shelf of 100 to $300 \mathrm{~m}$ depth, with complex bathymetry and many deep-water coastal fjords and embayments (Fig. 1). In 2002, 7 cruises were conducted in March, April, May, July, August, October and December. Egg production work was executed at 4 stations distributed along the Seward line from inshore to just past the shelf break (i.e. Gak1, 4, 9, 13), plus 1 station along the western inner passage of Prince William Sound (PWS2) where the depth is 500 to $800 \mathrm{~m}$. Water samples at these stations were collected by Niskin bottles for fluorometric estimation of chlorophyll a con- centration and averaged over the upper $40 \mathrm{~m}$ of the water column (D. A. Stockwell \& T. E. Whitledge unpubl. data).

Abundances of Metridia spp. females were determined from night-time collections employing a $1 \mathrm{~m}^{2}$ MOCNESS fitted with $505 \mu \mathrm{m}$ mesh nets fishing the upper $100 \mathrm{~m}$ at $1 \mathrm{~m} \mathrm{~s}^{-1}$ in five $20 \mathrm{~m}$ strata (see Coyle \& Pinchuk 2003). All females for egg production experiments were taken from an additional $100 \mu \mathrm{m}$ mesh net equipped with non-filtering cod-ends fished in the upper $50 \mathrm{~m}$ for several minutes at less than $1 \mathrm{~m} \mathrm{~s}^{-1}$. Samples were diluted immediately with ambient seawater, sorted within 0.5 to $2 \mathrm{~h}$, and placed individually in $50 \mathrm{ml}$ polycarbonate towers inserted into polystyrene 6 well tissue culture plates. Silicone O-rings provided a watertight seal between the towers and plate wells. The bottom of the towers were fitted with $200 \mu \mathrm{m}$ (for M. pacifica), or $400 \mu \mathrm{m}$ (for M. okhotensis) Nitex mesh that was held $\sim 0.5 \mathrm{~cm}$ above the bottom of the plate. Incubations of 48 active females per species were maintained at constant near ambient sea-surface temperature under natural lighting cycles. Incubations were terminated in the morning after 1 to $1.5 \mathrm{~d}$ of incubation. Water was removed from the towers with a large pipette fitted with $30 \mu \mathrm{m}$ mesh over the tip. The position of the pipette tip was constantly adjusted to keep it immediately below the water's surface to minimize disturbance of deeper layers. When $\sim 1 \mathrm{~cm}$ of water remained, the tower was removed from the plate, and the female backwashed off the mesh. This procedure rarely disturbed the eggs in the bottom of the multi-well.

Metridia spp. eggs were counted in their original positions within 1 to $2 \mathrm{~h}$ after dismantling the towers. Eggs were usually found in single, distinct clusters. Clutches laid on successive evenings could be distinguished not only by their spatial location, but also by noting the phase of embryonic development. Eggs were further distinguished as developing normally, infertile, or as having compromised development. As secondary production is defined as the 'elaboration of tissue, regardless of its fate' (Downing \& Rigler 1984), we include all these eggs types in our estimates. This assumption would clearly overestimate the values appropriate for population fecundity models if abnormal development is reflective of that in situ, rather than a consequence of handling and techniques. During 2 cruises, side-by-side comparisons of this method were made to mutli-well plates without towers
Fig. 1. Study area in the Gulf of Alaska. Four sites along the Seward line (Gak1, $4,9,13)$ plus the northern-most station in Prince William Sound (PWS2) were utilized for egg production experiments 
installed (volume $\sim 10 \mathrm{ml}$ ), and the more traditional methods of placing individual females in $250 \mathrm{ml}$ bottles, or groups of 4 females in $1000 \mathrm{ml}$ tissue culture flasks (Runge \& Roff 2000). For the bottles and flasks, females and eggs were concentrated onto a $35 \mu \mathrm{m}$ mesh at the termination of the experiment.

Individual females and eggs were then preserved for later measurement using a computer-assisted system (Roff \& Hopcroft 1986). Female weights were predicted from a length-dry weight equation obtained using a mixture of females from both species at times when females were rich in lipids: $\log \mathrm{DW}=-8.459+3.203 \log$ PL $\left(r^{2}=0.95, n=16\right)$, where DW is dry weight $(\mu \mathrm{g})$ and PL is prosome length $(\mu \mathrm{m})$. Female dry weights were determined to $\pm 0.1 \mu \mathrm{g}$ using a Cahn Microbalance on pre-weighted pans, after drying at $55^{\circ} \mathrm{C}$ for $24 \mathrm{~h}$. Egg weight was predicted from egg diameter, assuming a

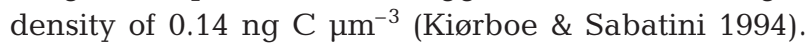
Egg carbon was converted to ash-free dry weight (AFDW) assuming carbon as $40 \%$ of AFDW, and AFDW was assumed to be $90 \%$ of dry weight (Hirst \& Bunker 2003). Linear regressions and curve fitting were carried out using SigmaPlot V8.0.

\section{RESULTS}

Although absolute abundances fluctuated between stations and over time, Metridia pacifica females could be found in surface waters at all stations throughout the year (Fig. 2), but were rare in December. In contrast, $M$. okhotensis was only found reliably inside Prince William Sound, and less reliably at Gak1, which is downstream in the Alaska Coastal Current that flows through the Sound. Female $M$. okhotensis became uncommon in surface waters after May once this layer warmed, although females were observed all yearround in deeper waters of the Sound.

Chlorophyll a peaked in April within the Sound and at Gak1, reaching values as high as $14 \mathrm{mg} \mathrm{m}^{-3}$, but was

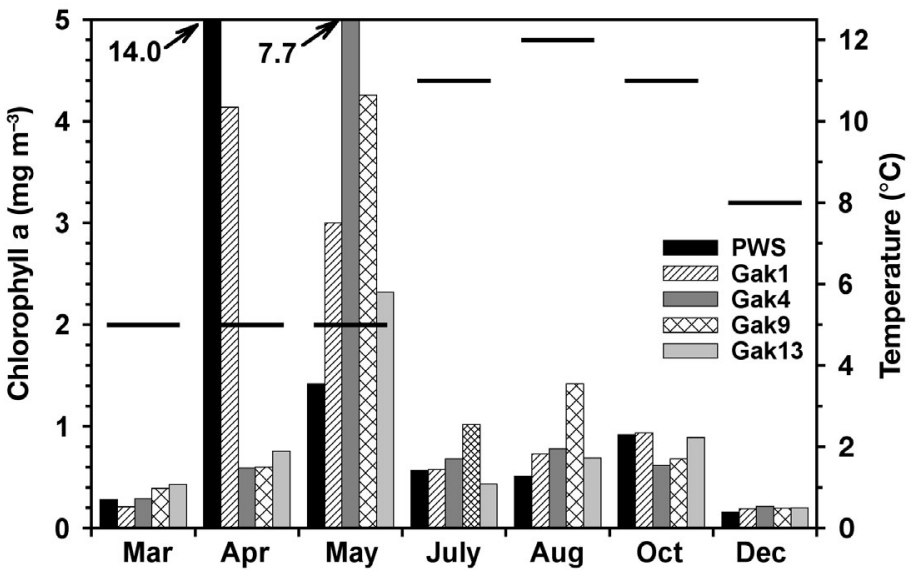

Fig. 3. Chlorophyll a concentration at experimental sites in the Gulf of Alaska during 2002 averaged over the upper $40 \mathrm{~m}$. Incubation temperatures, indicated by horizontal lines, were set to reflect the temperature of the upper mixed layer. PWS: Prince William Sound

delayed until May in more offshore waters (Fig. 3). Mixed layer water temperature was typically $\sim 5^{\circ} \mathrm{C}$ from March to May, and increased to over $14^{\circ} \mathrm{C}$ within Prince William Sound during July and August. Nonetheless, to reflect the temperatures more typical of the main sampling line, incubator temperatures during summer were limited to $12^{\circ} \mathrm{C}$ (Fig. 3).

Varying prevalence of the different egg types was observed. In March, none of the eggs laid appeared to develop normally (Fig. 4), and although this improved in April and May, it was generally less than $50 \%$ for Metridia pacifica. In contrast, most $M$. pacifica eggs laid in July, August and October developed normally; the single clutch laid in December failed to develop. Averaged over all experiments, $49 \%$ of $M$. pacifica eggs did not develop normally. M. okhotensis had a slightly different pattern, with a higher percentage of normally developing eggs in April and May. The abnormal egg category consisted primarily of eggs with either an absent or compromised membrane that

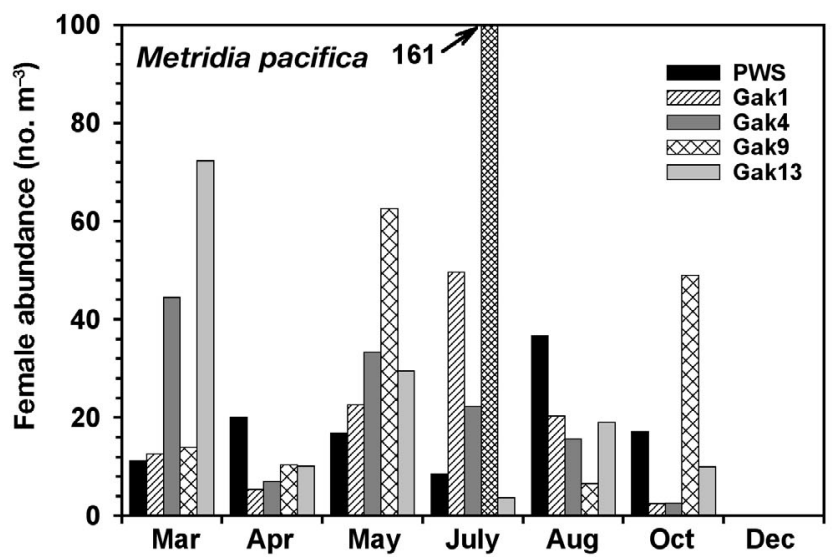

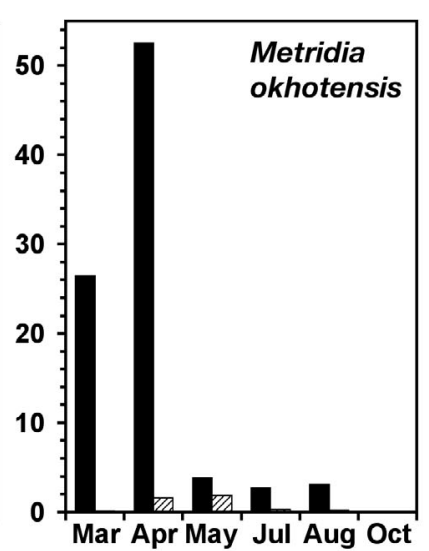

Fig. 2. Metridia pacifica and M. okhotensis. Abundance of females in the Gulf of Alaska during 2002. M. okhotensis was undetected at Gak4, 9 and 13 in all samples. MOCNESS samples are not available for the December cruise. PWS: Prince William Sound 

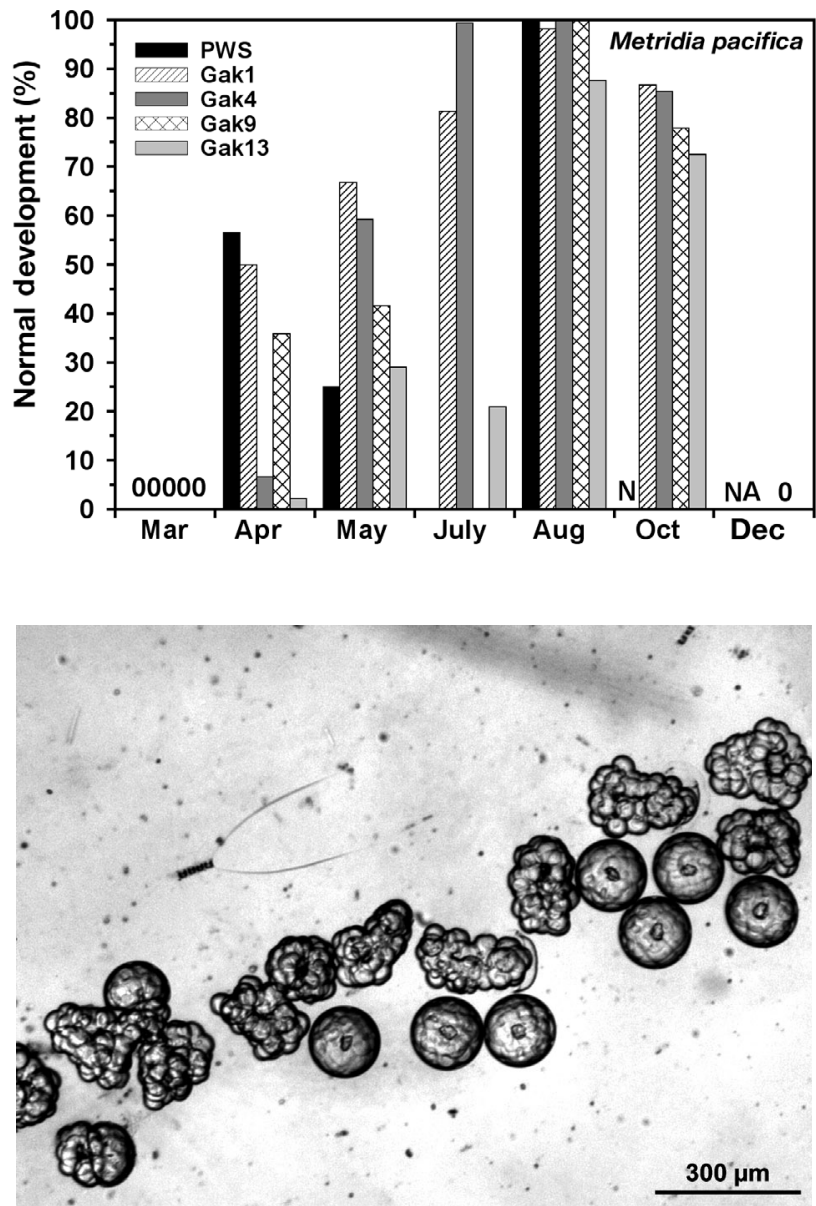

Fig. 5. Metridia pacifica. The 2 most commonly observed egg states: eggs undergoing normal development, and eggs that have lost their membrane and cellular cohesion. Both are at $\sim 32$ cell stage of embryonic development in this example

continued to divide eventually forming unorganized piles of undifferentiated cells (Fig. 5). Infertile eggs, that maintained their integrity but never divided, were relatively rare, seldom being more than 2 or 3 per clutch. Egg-sized spheres, that lacked a membrane, never divided, began to disintegrate rapidly, and were slightly more common in recently laid clutches; their numbers are likely underestimated.

Based on both direct observations during experimental set-up, and the observed stage of embryonic development during experimental break-down, most eggs appeared to be laid just before dawn ( 04:00 to 06:00 $\mathrm{h}$ depending on the time of year). Females in experiments set up in the first half of the night were often found with 2 clutches of similar number but with a vastly different developmental stage. In contrast, females in experiments set-up near or after dawn, typically had only 1 clutch. Successive night clutches were less common in March, and most common in May.

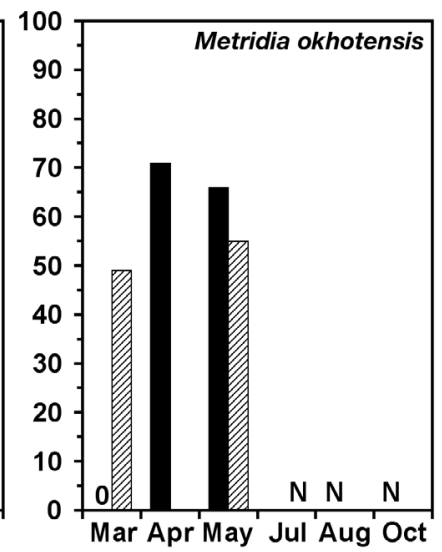

Fig. 4. Metridia pacifica and M. okhotensis. Percentage of eggs undergoing normal development during incubations in the Gulf of Alaska during 2002. Missing bars: no experiment; 0: females produced no normal eggs; N: no eggs were produced; A: females were absent from the collection site

When experiments were set up near or after dawn, egg production on the first night was consistently low and discounted. When few clutches were laid on the second night (as happened consistently in July and August), we considered only those clutches laid on the first night. Not surprisingly, abnormalities were more obvious in older clutches; therefore, our methods likely underestimate the true percentage of abnormal eggs for the most recent night's clutches. No attempt was made to establish the hatching success of normally developing eggs; however, in July and August, when incubation temperature was highest, experimental duration frequently approached hatching time, and high rates of hatching success were noted.

Females of both species were often observed with large lipid stores. Prosome length of females showed considerable seasonal variation in Metridia pacifica, with minimums in March (1600 to $1700 \mu \mathrm{m})$ and maximums in May (1950 to $2200 \mu \mathrm{m})$, and were relatively constant for the remainder of the year $(\sim 1700$ to $1800 \mu \mathrm{m})$. Some inter-station differences occurred within the sampling period, but there was no consistent station differences over the annual cycle (Fig. 6). In contrast, $M$. okhotensis showed no seasonal variation in prosome length, remaining at $\sim 2600 \mu \mathrm{m}$. Average clutch size tracked prosome length in $M$. pacifica (Fig. 6), but showed more pronounced seasonal variation. Considering all stations, average clutch size appeared to be lowest in March ( 12 eggs), greatest in May ( 49 eggs), and relatively similar across most other months, with no systematic patterns across stations (although notably, egg production shut down in Prince William Sound during October). The December data is less extensive than other months, and with the exception of a single female, no eggs were produced. Maximum clutch size produced by an individual M. pacifica was 103 eggs in May, with several females producing clutches of similar magnitude. Mean egg diameter in M. pacifica ranged from 140 to $150 \mu \mathrm{m}$. M. okhotensis produced larger clutches than M. pacifica (i.e. up to a 

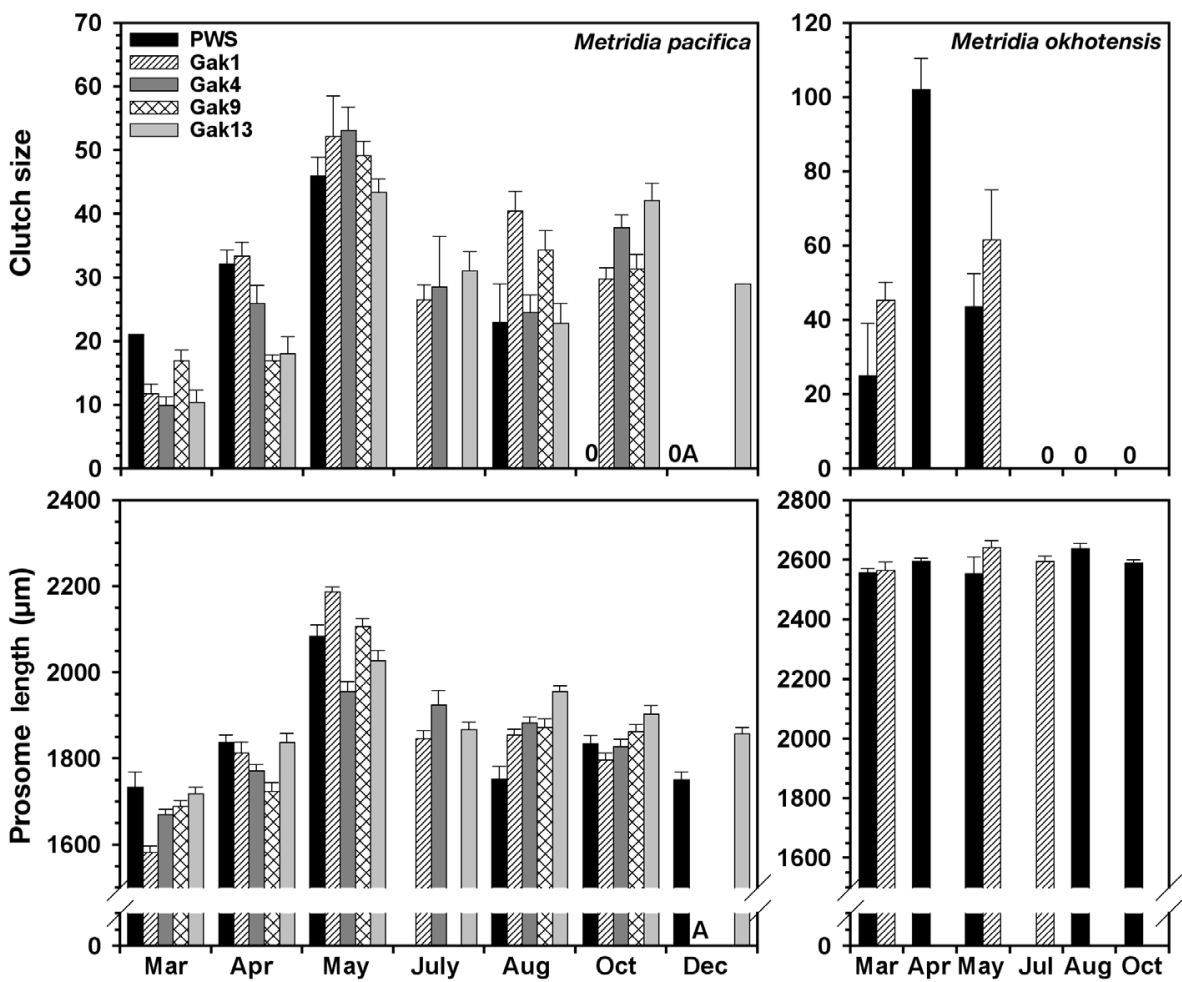

Fig. 6. Metridia pacifica and M. okhotensis. Egg clutch size and prosome length of females in the Gulf of Alaska during 2002. Standard errors of means indicated. 0 : females produced no normal eggs; A: females were absent from the collection site

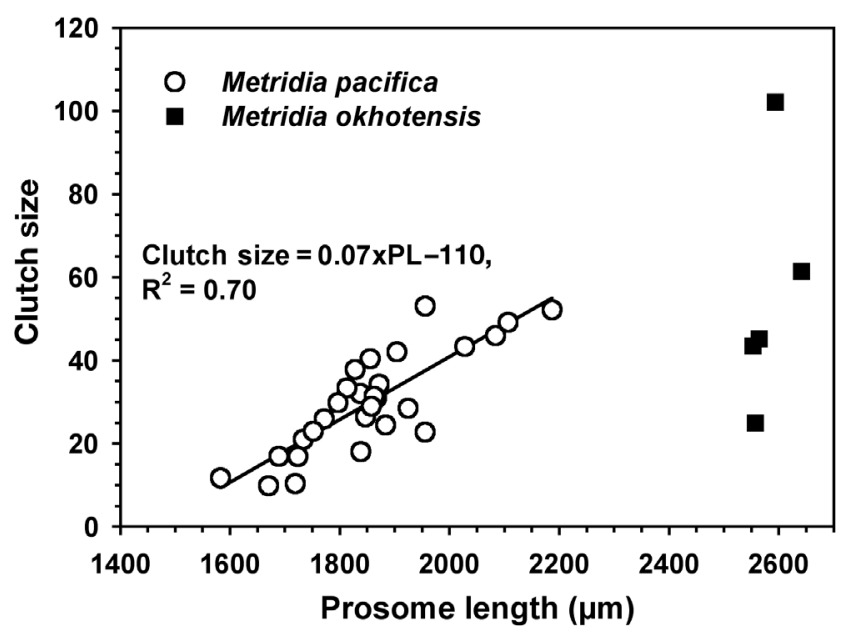

Fig. 7. Metridia pacifica and M. okhotensis. Relationship between size of the females of the 2 species (as prosome length) and the average number of eggs in the clutches produced for each experiment. Experiments where no clutches were produced have been excluded

maximum of 148 eggs by an individual) and larger eggs (170 to $180 \mu \mathrm{m}$ diameter), but unlike M. pacifica, egg laying was restricted to March through May. Average clutch size was related to female prosome length in $M$. pacifica $\left(\mathrm{r}^{2}=0.63\right)$, but not in $M$. okhotensis (Fig. 7).
Accounting for the females that did not produce eggs, Metridia pacifica populations averaged 16 eggs female ${ }^{-1} \mathrm{~d}^{-1}$ from March through October (Fig. 8), with egg production rates (EPRs) consistently lower in March (average 3 eggs female $\mathrm{e}^{-1} \mathrm{~d}^{-1}$, and generally highest in May (average 30 eggs female ${ }^{-1} \mathrm{~d}^{-1}$ ). M. okhotensis populations averaged 28 eggs female ${ }^{-1}$ $\mathrm{d}^{-1}$ in April and May, had limited egg release in March, and produced no eggs during summer and fall. The $M$. pacifica females that produced clutches typically released the equivalent of 10 to $20 \%$ of their body weight as eggs (Fig. 9), with lower values in March, and consistently higher values in May. M. okhotensis that produced clutches typically released the equivalent of $25 \%$ of their body weight as eggs in April and May. Accounting for those females that did not release eggs, specific egg production (SEP) for the population of $M$. pacifica was only 1 to $4 \%$ in March, negligible in December, but averaged $10 \%$ in the other months. The SEP seasonal pattern appears to be more stable than that observed for clutch size or EPR, as a higher percentage of females produced clutches during summer and fall than during spring, and because SEP accounts for seasonal changes in female body size. SEP for the population of $M$. okhotensis mirrored its EPR, averaging $11 \%$ over April and May.

Much of the observed patterns between stations could be attributed to ambient chlorophyll concentrations, after adjusting for temperature (Fig. 10) by a $Q_{10}$ of 2.7 determined for food-saturated broadcasting adult copepods (Hirst \& Bunker 2003). Curves fit to Michaelis-Menten form (lower curves) described a large part of the variation (adjusted $\mathrm{r}^{2}$ of 0.59 or 0.69 dependent on the inclusion of the strongest outlying value: May, Gak1, lowest point). The data envelope was even better described by sigmoidal functions (Table 1), after removal of the 4 low out-lying values: both Chapman and Hill equations described similar levels of variation (adjusted $\mathrm{r}^{2}$ of $\sim 0.84$ ) and although all 3 fitted parameters were significant for both of these curves, they were most significant for the Hill equation. All equations are consistent in indicating that food-saturated rates at $5^{\circ} \mathrm{C}$ result in 17 to $18 \%$ of their body weight going into egg production each day, 

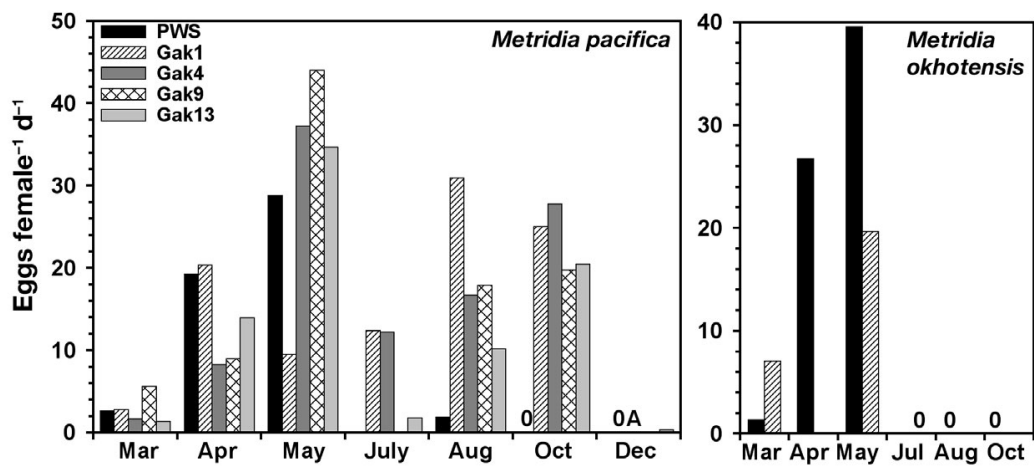

Fig. 8. Metridia pacifica and M. okhotensis. Egg production rate for the populations of females incubated in the Gulf of Alaska during 2002. Missing bars: no experiment; 0 : females produced no clutches; A: females were absent from the collection site
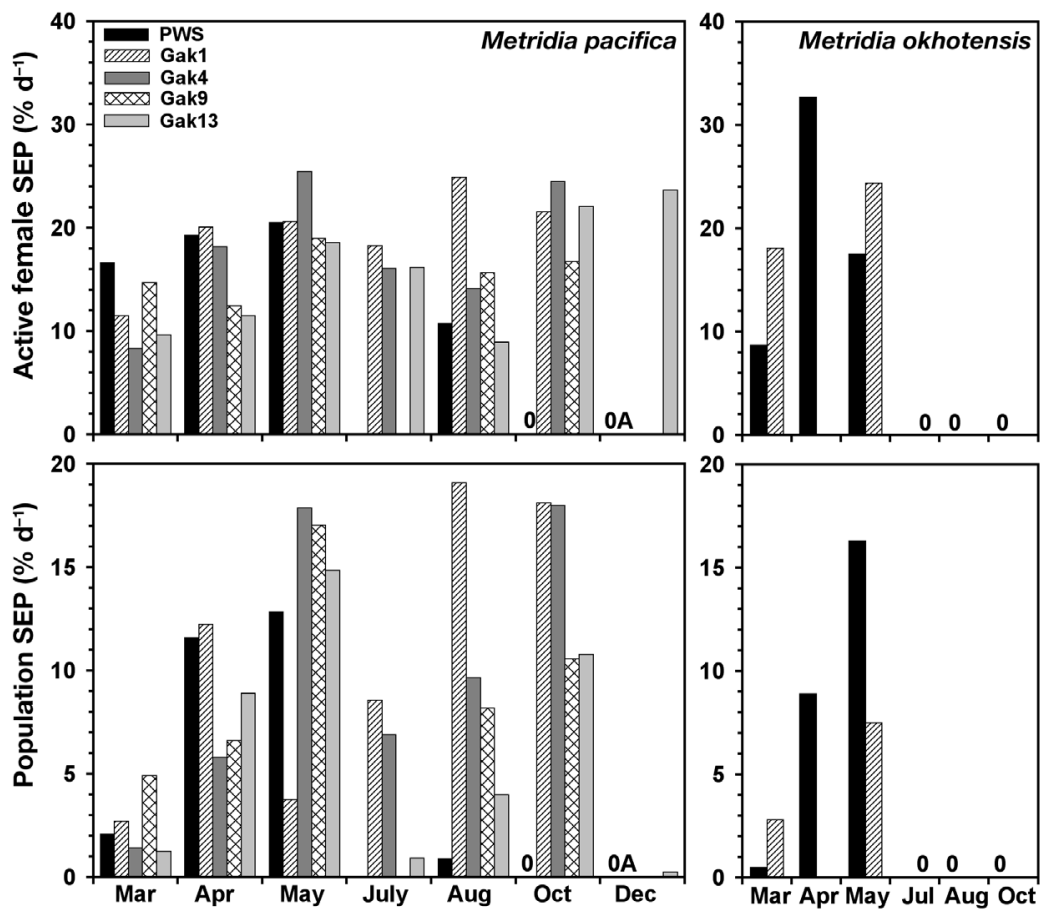

Fig. 9. Metridia pacifica and M. okhotensis. Specific egg production (SEP) of only those females producing eggs, and for the populations of females incubated in the Gulf of Alaska during 2002. Missing bars: no experiment; 0 : females produced no clutches; A: females were absent from the collection site ment, when in fact, significant numbers of eggs were developing abnormally. Empty and/or damaged egg-cases were only rarely found. This suggests abnormal eggs are most likely dispersed by activity of the females, and not cannibalism of eggs per se. Initial trials using multiwells alone, were similarly low, and frequently gave the impression that no egg production was occurring (Table 2).

\section{DISCUSSION}

In the Gulf of Alaska, Metridia species appear to undergo cycles of egg production related to annual cycles of phytoplankton biomass and temperature that are typical for most copepods (e.g. J. M. Napp unpubl. data, R. R. Hopcroft unpubl. data). The 2 species differ in that multiple generations of $M$. pacifica occur annually in the Gulf of Alaska, while only 1 generation occurs for $M$. okhotensis. Sampling was not conducted frequently enough to conclusively determine whether 2 (Hirakawa \& Imamura 1993, Padmavati et al. 2004) or 3 (Batchelder 1985) generations per year occur for $M$. pacifica in the study area; however, based on the sustained reproductive activity, patterns of female abun-dance, and knowledge of temperature-dependent growth in the laboratory (Padmavati \& Ikeda 2002), 3 are most likely. Similar to observations made for $M$. lucens (McLaren et al. 1989), over-wintering females are small compared to other generations, and those females completing development during the spring bloom are largest. In contrast, results from this study are more consistent with a single year life cycle for $M$. okhotensis, rather than a 2 y life cycle proposed with half saturation occurring at 1 to $1.5 \mathrm{mg}$ chlorophyll $a \mathrm{~m}^{-3}$.

Results from side-by-side methodological comparisons emphasize the magnitude of error that could be associated with more traditional egg production methodology (Table 2). When using multi-wells or bottles, estimates of EPR were one-third to one-tenth of those obtained using the towers. Within a given contrast, all alternate methods appeared to yield similar results and gave the impression that most of the eggs were undergoing normal develop- for this species at slightly colder temperatures (Padmavati et al. 2004).

The daily specific rates of egg production for both species are consistent with those expected for copepods of these sizes, at these temperatures (Hirst \& Lampitt 1998, Hirst \& Bunker 2003). Rates of Metridia specific egg production are also comparable to those of other calanoid species in the Gulf of Alaska that have been simultaneously determined (J. M. Napp unpubl. data, R. R. Hopcroft unpubl. data). This is in sharp con- 


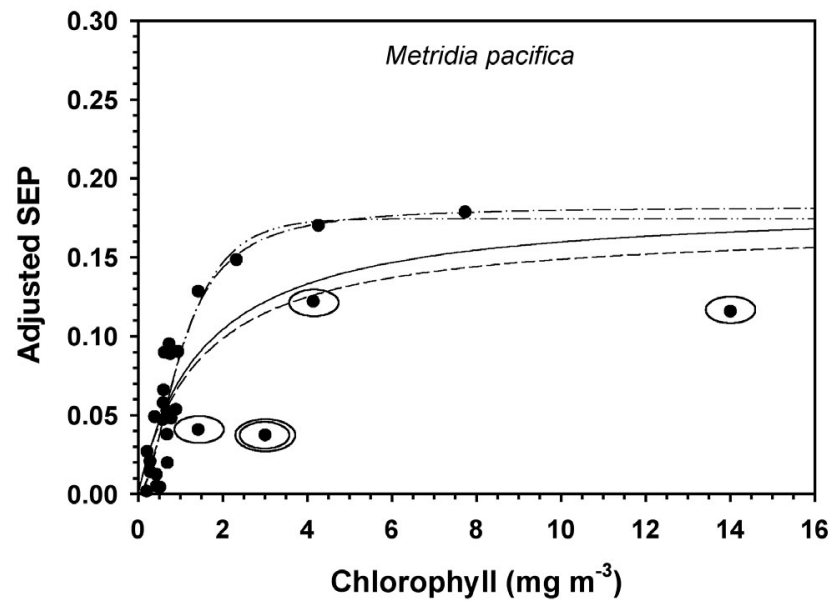

Fig. 10. Metridia pacifica. Functional relationship between population specific egg production (SEP) and chlorophyll a concentration. All data corrected to $5^{\circ} \mathrm{C}$ using a $Q_{10}$ of 2.7 . Curves fit to Michaelis-Menten form using all data (-- - ) or after removal of the strongest outlying value $(-)$ that occurred in May at Gak1 (point double circled). Sigmoidal Chapman (-. -) and Hill (-..-) functions fit after removal of the 4 low out-lying values (circled) trast to the only 2 rates of egg production determined for M. pacifica: 6 eggs female ${ }^{-1} \mathrm{~d}^{-1}$ (Batchelder \& Miller 1989) determined at Ocean Station $P$ and off the Oregon Coast and 0.2 to 5.6 eggs female ${ }^{-1} \mathrm{~d}^{-1}$ in Toyama Bay, Japan (Hirakawa \& Imamura 1993). In fact, all the published rates for the species within this genus are low: $M$. lucens ranges from 0 to 3.4 eggs female $\mathrm{d}^{-1}$ at 5 to $7^{\circ} \mathrm{C}$ (Nielsen \& Richardson 1989, Hay et al. 1991) and $2.1 \pm 0.9$ at 9 to $23^{\circ} \mathrm{C}$ (Richardson et al. 2001); $M$. longa ranges from 0.2 to 8.3 eggs female $\mathrm{d}^{-1}$ at 1.5 to $2.5^{\circ} \mathrm{C}$ (Buskey \& Sterns 1991, Hansen et al. 1996); M. gerlachei ranges from 0 to 6.2 eggs female $\mathrm{e}^{-1} \mathrm{~d}^{-1}$ at 0 to $4^{\circ} \mathrm{C}$ (summarized in SchnackSchiel 2001). All of these estimates have been obtained by harvesting the eggs with screens, and most by incubating groups of females. Maximum individual clutch size has only been reported in 2 cases: M. gerlachei, 42 eggs (Schnack-Schiel 2001), and M. lucens, 28 eggs (Richardson et al. 2001). Curiously, McLaren et al. (1989) 'observed copious egg production by females (of M. lucens) soon after being brought to the laboratory' (p. 569) but never determined their EPR.

Table 1. Metridia pacifica. The relationship between specific egg production (SEP) and chlorophyll a (Chl) after standardizing rates to $5^{\circ} \mathrm{C}$. SEP $\mathrm{Sax}_{\max }$ is the food-saturated SEP. $K_{\mathrm{d}}$ is the chlorophyll concentration at half saturation. The exponent b is simply a fitted parameter. $\mathrm{p}<0.0001$ for all relationships

\begin{tabular}{|c|c|c|c|c|c|}
\hline Function & Equation & $\mathrm{SEP}_{\max } \pm \mathrm{SE}$ & $K_{\mathrm{d}} \pm \mathrm{SE}$ & Exponent & Adjusted $r^{2}$ \\
\hline Michaelis-Menten (all data) & $\mathrm{SEP}=\frac{\mathrm{SEP}_{\max } \mathrm{Chl}}{\left(K_{\mathrm{d}}+\mathrm{Chl}\right)}$ & $0.17 \pm 0.03$ & $1.46 \pm 0.52$ & & 0.59 \\
\hline $\begin{array}{l}\text { Michaelis-Menten } \\
\text { (1 outlier removed) }\end{array}$ & $\mathrm{SEP}=\frac{\mathrm{SEP}_{\max } \mathrm{Chl}}{\left(K_{\mathrm{d}}+\mathrm{Chl}\right)}$ & $0.18 \pm 0.03$ & $1.53 \pm 0.45$ & & 0.69 \\
\hline Chapman & $\mathrm{SEP}=\operatorname{SEP}_{\max }\left(1-\mathrm{e}^{-K_{\mathrm{d}} \mathrm{Chl}}\right)^{\mathrm{b}}$ & $0.17 \pm 0.02$ & $1.24 \pm 0.46$ & $2.01 \pm 0.76$ & 0.82 \\
\hline Hill & $\mathrm{SEP}=\frac{\mathrm{SEP}_{\max } C h l^{\mathrm{b}}}{\left(K_{\mathrm{d}}^{\mathrm{b}}+\mathrm{Chl}^{\mathrm{b}}\right)}$ & $0.18 \pm 0.02$ & $1.02 \pm 0.18$ & $1.95 \pm 0.47$ & 0.83 \\
\hline
\end{tabular}

Table 2. Comparison of egg production towers to other egg production methods, such as individuals in multi-wells, individuals in $250 \mathrm{ml}$ bottles or groups of 4 females in $1000 \mathrm{ml}$ flasks. Preliminary experiments in multi-wells alone presented for comparison. EPR: egg production rate

\begin{tabular}{|c|c|c|c|c|c|c|c|}
\hline & Method & No. of females & No. of clutches & Clutch size & $\begin{array}{l}\text { First clutch } \\
\text { (\% normal) }\end{array}$ & $\begin{array}{c}\text { Second clutch } \\
\text { (\% normal) }\end{array}$ & EPR \\
\hline \multirow[t]{2}{*}{ May-02 (Gak4) } & Towers & 48 & 49 & $53.1 \pm 3.6$ & 59 & 88 & 37.3 \\
\hline & Multi-wells & 48 & 43 & $23.5 \pm 4.0$ & 94 & 93 & 12.2 \\
\hline \multirow[t]{4}{*}{ May-04 (Gak4) } & Towers & 48 & 32 & $36.0 \pm 2.0$ & 68 & 79 & 24.0 \\
\hline & Multi-wells & 48 & 13 & $11.9 \pm 1.6$ & 100 & 99 & 3.2 \\
\hline & Bottles: 1o & 39 & 8 & $12.8 \pm 2.5$ & - & - & 2.6 \\
\hline & Flask: $4 \rho^{+}$ & 40 & - & - & - & - & 2.4 \\
\hline \multirow[t]{3}{*}{ May-04 (Gak10) } & Towers & 48 & 27 & $41.8 \pm 2.1$ & 9 & 1 & 23.5 \\
\hline & Bottles: 10 & 39 & 12 & $7.5 \pm 2.7$ & - & - & 2.3 \\
\hline & Flask: 4 o & 40 & - & - & - & - & 4.8 \\
\hline Apr-01 (PWS2) & Multi-wells & 57 & 25 & $8.4 \pm 1.2$ & 94 & - & 3.7 \\
\hline May-01 (PWS2) & Multi-wells & 40 & 0 & - & - & - & 0 \\
\hline July-01 (Gak1) & Multi-wells & 40 & 0 & - & - & - & 0 \\
\hline July-01 (PWS2) & Multi-wells & 40 & 0 & - & - & - & 0 \\
\hline
\end{tabular}


Compared to other studied species, observations from all Metridia species yield rates that would be reconcilable with our observations that $M$. pacifica and M. okhotensis egg production is not adequately assessed by traditional methods. If such a generalization is correct, undoubtedly, this has contributed to the impression that Metridia has unusually low egg production. Averaged over all experiments, $49 \%$ of the $M$. pacifica eggs did not develop normally, and would not have been recovered if they had been concentrated by screening down the experiment rather than observing them where they were laid. In a side-by-side methodological comparison, standard methods underestimated EPR by 3- to 10-fold. In fact, the determination of unacceptably low egg production by some researchers has either discouraged them from publishing their results, and/or stifled their interest in more routine determination of egg production for Metridia spp.

Under experimental conditions, eggs without membranes consistently failed to undergo normal development and hatch. It is unclear whether abnormal development is reflective of what is happening in the water column, or only in the experiments. It is unlikely that a methodological artifact is solely responsible for the fragility or lack of egg membranes. In concurrent experiments with other calanoid species and the same techniques, abnormal development was either absent or minimal. If the methodology is responsible for abnormal development in Metridia spp. eggs, then one would not expect the problem to disappear during the summer. Furthermore, during the spring, when membranes are typically absent, we observed eggs that lack a membrane even immediately after being laid. Although incubation temperatures are lowest during spring, when bad eggs are most common, Metridia spp. does not have problems with spring recruitment and population maintenance in the study area or over its entire sub-arctic range (e.g. Batchelder 1985, Vidal \& Smith 1986, Hirakawa \& Imamura 1993, Padmavati et al. 2004), so cold temperatures are not likely to be the problem. Conversely, one would expect the developmental problem to be magnified at higher temperatures, when developmental rates are maximal; yet, this is when development proceeds most successfully.

This leaves the possibility that either a key nutritional requirement is absent in the diet (or the animal's lipid stores), or that some element in the diet interferes with the production of normal eggs during the spring. There has been active debate for over a decade that when diatoms dominate the phytoplankton community, egg production and viability are negatively impacted due to adverse chemicals (e.g. Miralto et al. 1999, 2003, Irigoien et al. 2002). Although we cannot preclude that chemicals in prey such as diatoms are responsible (Ianora et al. 2004), such chemicals appear to have a limited or less obvious impact on other species that are reproductively active concurrently in the Gulf of Alaska during the spring 'bloom'. Metridia species may simply be more susceptible than other co-occurring species to the aldehydes produced by diatoms. Alternatively, the problem could be due to the absence of some element in the diet; one that is not stored along with the large lipid stores commonly observed in March, April and, to a lesser extent, May. In the latter scenario, females that have the energetic reserves after over-wintering begin to produce eggs, but essential compounds required for the production of a normal egg membrane (and potentially other cellular functions) are missing. Future activities will be directed towards examining the relationship between the prevalence of diatoms and abnormal eggs.

Regardless of the underlying cause, it is clear that the standard techniques developed for estimating egg production, may not be appropriate for all species of copepods. We now have a rough framework of the relationship between (female) growth rate (Hirst \& Bunker 2003) or fecundity (Bunker \& Hirst 2004), temperature, body size, and resources that allow us to see whether experimental data are consistent with these patterns. The data in this study are clearly consistent with the forms of those relationships. When data appear anomalous, or even paradoxical, as may be the case with all Metridia species, methodology should be more closely scrutinized before such rates are simply considered 'exceptions to the rule'.

Acknowledgements. We thank the captain and crew of the RV 'Alpha Helix', and all seagoing colleagues in the GLOBEC Gulf of Alaska LTOP program for various forms of assistance in execution of this work. K. Coyle kindly provided data on Metridia abundance, while D. Stockwell and T. Whitledge provided ambient chlorophyll data for all stations. This is contribution number 489 of the US GLOBEC program, jointly funded by the National Science Foundation and the National Oceanic and Atmospheric Administration under NSF Grant OCE-0105236.

\section{LITERATURE CITED}

Batchelder HP (1985) Seasonal abundance, vertical distribution, and life history of Metridia pacifica (Copepoda: Calanoida) in the oceanic subarctic Pacific. Deep-Sea Res 32:949-964

Batchelder HP, Miller CA (1989) Life history and population dynamics of Metridia pacifica: results from simulation modelling. Ecol Model 48:113-136

Brodsky KA (1967) Calanoida of the far-eastern seas and the polar basin of the USSR. Israel Program for Scientific Translations, Jerusalem

Brodsky KA (1977) The description of male Metridia okhotensis Brodsky (Calanoida, Metridiidae). In: Brodsky KA, Vyshkartseva NV (eds) Marine plankton (systematics and faunistics). Explorations of the marine fauna, 20. Leningrad, p 4-5 (in Russian)

Bunker AJ, Hirst AG (2004) Fecundility of marine planktonic 
copepods: global rates and patterns in relation to chlorophyll a temperature and body weight. Mar Ecol Prog Ser 279:161-181

Buskey EJ, Stearns DE (1991) The effects of starvation on bioluminescence potential and egg release of the copepod Metridia longa. J Plankton Res 13:885-893

Cooney R, Coyle KO, Stockmar E, Stark C (2001) Seasonality in surface-layer net zooplankton communities in Prince William Sound, Alaska. Fish Oceanogr 10(Suppl 1):97-109

Coyle KO, Pinchuk AI (2003) Annual cycle of zooplankton abundance, biomass and production on the northern Gulf of Alaska shelf, October 1997 through October 2000. Fish Oceanogr 12:327-351

Coyle KO, Paul AJ, Ziemann DA (1990) Copepod populations during the spring bloom in an Alaskan subarctic embayment. J Plankton Res 12:759-797

Downing JA, Rigler FH (1984) A manual on methods for the assessment of secondary productivity in fresh waters. Blackwell Scientific, London

Gardner GA, Szabo I (1982) British Columbia pelagic marine Copepoda: an identification manual and annotated bibliography. Can Spec Publ Fish Aquat Sci 62:1-536

Hansen B, Christiansen S, Pedersen G (1996) Plankton dynamics in the marginal ice zone of the central Barents Sea during spring: carbon flow and structure of the grazer food chain. Polar Biol 16:115-128

Hay SJ, Kiørboe T, Matthews A (1991) Zooplankton biomass and production in the North Sea during the Autumn Circulation Experiment, October 1987-March 1988. Cont Shelf Res 11:1453-1476

Hirakawa K, Imamura A (1993) Seasonal abundance and life history of Metridia pacifica (Copepoda: Calanoida) in Toyama Bay, southern Japan Sea. Bull Plankton Soc Jpn 40:41-54

Hirst AG, Lampitt RS (1998) Towards a global model of in situ weight-specific growth in marine planktonic copepods. Mar Biol 132:247-257

Hirst AG, Bunker AJ (2003) Growth of marine planktonic copepods: global rates and patterns in relation to chlorophyll a, temperature, and body weight. Limnol Oceanogr 48:1988-2010

Hopcroft RR, Clarke C, Chavez FP (2002) Copepod communities in Monterey Bay during the 1997 to 1999 El Niño and La Niña. Prog Oceanogr 54:251-263

Huntley ME, Escritor F (1992) Ecology of Metridia gerlachei Giesbrecht in the western Bransfield Strait, Antarctica. Deep-Sea Res 39:1027-1055

Ianora A, Miralto A, Poulet SA, Carotenuto Y and 8 others (2004) Aldehyde suppression of copepod recruitment in blooms of a ubiquitous planktonic diatom. Nature 429: 403-407

Incze LS, Siefert DW, Napp JM (1997) Mesozooplankton of Shelikof Strait, Alaska: abundance and community composition. Cont Shelf Res 17:287-305

Irigoien X, Harris RP, Verheye HM, Joly PB and 14 others (2002) Copepod hatching success in marine ecosystems with high diatom concentrations. Nature 419:387-389

Kiørboe T, Sabatini M (1994) Reproductive and life cycle strategies in egg-carrying cyclopoid and free-spawning calanoid copepods. J Plankton Res 16:1353-1366

Editorial responsibility: Michael Landry (Contributing Editor), La Jolla, California, USA
Mauchline J (1998) The biology of calanoid copepods. Advances in marine biology, Vol 33. Academic Press, London

McLaren IA, Tremblay MJ, Corkett CJ, Roff JC (1989) Copepod production on the Scotian Shelf based on life-history analyses and laboratory rearings. Can J Fish Aquat Sci 46: 560-583

Miralto A, Barone G, Romano G, Poulet SA and 6 others (1999) The insidious effect of diatoms on copepod reproduction. Nature 402:173-175

Miralto A, Guglielmo L, Zagami G, Buttino I, Granata A, Ianora A (2003) Inhibition of population growth in the copepods Acartia clausi and Calanus helgolandicus during diatom blooms. Mar Ecol Prog Ser 254:253-268

Nielsen TG, Richardson K (1989) Food chain structure of the North Sea plankton communities: seasonal variations of the role of the microbial loop. Mar Ecol Prog Ser 56:75-87

Ozaki K, Takeuchi T, Shiga N, Mito K (2001) Winter zooplankton biomass and population structure of calanoid copepods in the Bering Sea basin. Plankton Biol Ecol 48:46-51

Padmavati G, Ikeda T (2002) Development of Metridia pacifica (Crustacea: Copepoda) reared at different temperatures in the laboratory. Plankton Biol Ecol 49:93-96

Padmavati G, Ikeda T, Yamaguchi A (2004) Life cycle, population structure and vertical distribution of Metridia spp. (Copepoda: Calanoida) in the Oyashio region (NW Pacific Ocean). Mar Ecol Prog Ser 270:181-198

Rebstock GA (2001) Long-term stability of species composition in calanoid copepods off southern California. Mar Ecol Prog Ser 215:213-224

Richardson AJ, Verheye HM, Herbert V, Rogers C, Arendse LM (2001) Egg production, somatic growth and productivity of copepods in the Benguela Current system and Angola-Benguela Front. S Afr J Sci 97:251-256

Roff JC, Hopcroft RR (1986) High precision microcomputer based measuring system for ecological research. Can J Fish Aquat Sci 43:2044-2048

Runge JA, Roff JC (2000) The measurement of growth and reproductive rates. In: Harris RP, Weibe $\mathrm{PH}$, Lenz J, Skjoldal HR, Huntley M (eds) ICES zooplankton methodology manual. Academic Press, London, p 401-454

Schnack-Schiel SB (2001) Aspects of the study of the life cycles of Antarctic copepods. Hydrobiologia 453/454: $9-24$

Shebanova MA (1977) Distribution and age composition of Metridia okhotensis and Metridia pacifica (Copepoda: Calanoida) in epipelagial of the Okhotsk Sea. Izvestia TINRO 122:361-373 (in Russian)

Sherman K, Solow A, Jossi J, Kane J (1998) Biodiversity and abundance of zooplankton of the Northeast Shelf ecosystem. ICES J Mar Sci 55:730-738

Smith SL, Vidal J (1986) Variations in the distribution, abundance, and development of copepods in southeastern Bering Sea in 1980 and 1981. Cont Shelf Res 5:215-239

Vidal J, Smith SL (1986) Biomass, growth and development of populations of herbivorous zooplankton in the southeastern Bering Sea during spring. Deep-Sea Res 33:523-556

Weingartner TJ, Coyle KO, Finney B, Hopcroft RR and 15 others (2002) The Northeast Pacific GLOBEC program: coastal Gulf of Alaska. Oceanography 15:48-63

Submitted: August 25, 2003; Accepted: August 26, 2004

Proofs received from author(s): January 24, 2005 